\section{Factors affecting gastrointesti- nal parasite infections in goats in semi-arid rural ecosystems in India}

\author{
Dinesh Kumar Sharma, ${ }^{1}$ Ajoy Mandal² \\ 1Central Institute For Research on Goats, \\ Makhdoom PO, Mathura; ${ }^{2}$ Animal \\ Breeding Section, Eastern Regional \\ Station, National Dairy Research \\ Institute, Kalyani, India
}

\section{Abstract}

This study was undertaken in two adopted villages of a semi-arid zone of India (namely Mahuan and Bhahai) to assess the prevalence rates of different parasitic infections in goats and the various factors affecting them. In a 4years study, the effect of various factors like year and season of sampling, farmer's land holding, flock size, sex and age of the animals along with interactions, were observed and analyzed. The common parasites profile of both villages was equal. Coccidian infection in both villages (36.96 and 41.81 percent, respectively) was marked by the presence of Eimeria arliongi, E. ninakohlyakimovae, E. parva, E. caprina, $E$. alijevi species, while gastro-intestinal nematode infections (23.17 and 27.23 percent respectively) were dominated by the presence of Haemonchus contortus. The study revealed that different environmental factors, like farmer's land holding, herd size and age of the animal, significantly influenced the load of coccidian infection. Among nematode ones, the effects of factors like herd size and age of the animals were significant on fecal egg count, whereas for Moniezial infection sampling year, land holding capacity of farmers and flock size had significant effect on fecal egg count of animals. We can conclude that the interaction effect between sampling village per sampling year had only a significant effect on coccidian infection of goats $(\mathrm{P}<0.05)$.

\section{Introduction}

Parasitic infections are among the most serious problems faced by the goat-keepers worldwide. They result severe losses to goat production. Coccidia and gastrointestinal nematode (GIN) infections, mixed or single, are the major parasitic diseases influencing the goat industry in both tropical and temperate climates. ${ }^{1-3}$ In India, infections due to coccidia, particularly Eimeria and gastrointestinal nematodes are well recognized in goats and they may cause severe economic losses by lowering weight gains or possibly resulting in death. ${ }^{4-7}$ State of parasitic disease in a flock as such reflects the management quality, which in turn is governed by economic status of the flock owner. Many factors like number of animals, space provided, prophylactic and curative measures adopted along with labor input influence the parasitic load of a flock. All these factors directly or indirectly depend on financial strength of the goat owners. In India, goat rearing, as considered the source of subsistence of poor and landless farmers, is practiced in very resource bound conditions. Poor families with no other source of income generally choose to goat rearing and opt for more number of animals in limited space leading to high stocking rate. The resources available for successful goat rearing in villages vary from meager where the animals are kept on zero input to well-nourished stall-feeding. Further, up keeping of sheds, feed quality, hygiene in rural flocks are quite diversified and depend on input resources and stocking rates. Epidemiology of the single or mixed parasitic infections in any particular region in association with various factors influencing them has been a prerequisite for the development of appropriate control measures. The study was envisaged to study the Eimerian and gastrointestinal nematode infections in goats in rural ecosystem along with factors affecting them in prevailing conditions.

\section{Materials and Methods}

\section{Study location}

The study was conducted in the two villages namely, Mahuan and Bhahai, located in the vicinity of the Central Institute for Research on Goats, Makhdoom, Farah, Mathura, India (169 $\mathrm{m}$ MSL, $10^{\circ} \mathrm{N}$ and $78^{\circ} 02^{\prime} \mathrm{E}$ ) with a semi-arid climate. The villages, Mahuan and Bhahai, were about 6 and $15 \mathrm{Km}$ away from the Institute respectively. The distance between the two villages is about $8 \mathrm{Km}$. The selection of villages was based on the number of goats and approach from the institute. The goat population in both the villages was more than 500 animals in all. The soil of this area was sandy and vegetation composed of natural pasture and bush. The annual rainfall in this area was about $750 \mathrm{~mm}$, scattered during the months of June to September. Meteorological data of this location during the study period indicated that the temperature varied from $6^{\circ} \mathrm{C}$ to $30^{\circ} \mathrm{C}$ in winter and $21^{\circ} \mathrm{C}$ to $42^{\circ} \mathrm{C}$ in summer. Based on the meteorological data, the entire year was broadly classified in 4 seasons viz. winter (NovemberFebruary), summer (March-June), rainy (JulySeptember) and autumn (October).
Correspondence: Dinesh Kumar Sharma, Central Institute For Research on Goats, Makhdoom, P.O. Farah-281122, District-Mathura (UP), India. Tel. +91.056.527.63244 - Fax: +91.056.527.63246 E-mail: lkofwb@yahoo.co.in

Key words: parasite infections, goat, Eimeria and GI nematodes.

Acknowledgements: thanks are due to Director CIRG Makhdoom for financial and essential laboratory supports.

Contributions: DKS, collection, processing and examination of faecal samples to generate the basic data, compilation, tabulation and transformation of the data for statistical analysis, interpretation of results and preparation of manuscript; AM, statistical analysis, interpretation of result, preparation of manuscript.

Received for publication: 28 February 2013.

Revision received: 6 May 2013.

Accepted for publication: 14 May 2013.

This work is licensed under a Creative Commons Attribution NonCommercial 3.0 License (CC BYNC 3.0).

(C) Copyright D.K. Sharma and A. Mandal, 2013 Licensee PAGEPress srl, Italy

Veterinary Science Development 2013; 3:e5 doi:10.4081/vsd.2013.e5

\section{Description of experimental animals}

The goats under study, were of mixed type having predominance of Barbari breed in both the villages. The animals were generally maintained in extensive feeding system and the animals are allowed grazing for 7-8 hours on natural pasture. The grazing started in the morning hours of the day and continued until evening. During the extreme summer months, the grazing hours of the flocks were generally restricted to the cooler hours of the day. The farmers grazing land was usually common on the sides of roads and canals during monsoon and in the post-harvested fields in summers. Grazing was done mostly by old man and in few cases by the children/youth of the family. Primarily small and marginal farmers with low educational status reared goats. The farmers having few goats (1-5) generally practiced stall-feeding and these small flocks were kept in the vicinity of the goat keeper's house. They generally did not provide any supplement to their animals. Lopping of trees especially during lean season was also used. The goats were also fed on straw during lean periods. Generally animals were housed together and no specific housing was provided in these villages. Only improvised thatched housing was provided by large goat keepers whereas small 
and marginal goat keepers kept their animals in the family houses. The numbers of large flocks were however more in Bhahai village than the Mahuan village. The flooring of houses was mud based (Kachcha) in all cases. No dipping was practiced in the farmers' flock. Treatment of sick animals was looked at nearby veterinary hospital or from quacks. Two deworming, the pre and post monsoon, with Albendazole $(10 \mathrm{mg} / \mathrm{Kg} \mathrm{BW})$ were practiced however, no report of anthelmintic resistance was available.

\section{Data and statistical analysis}

Parasitological data were collected from the goats of both villages over a period of 4 years i.e. from 1999 to 2003, following natural challenge. Animals of both sexes and varying age (up to 12 months) were considered for study excluding the pregnant or lactating goats. Fecal samples were collected per rectum on routine basis at different seasons of the study. Each animal was sampled twice in any particular sampling season (interval at least 3 weeks). The individual fecal samples were then processed for fecal egg counts (EPG) and oocyst count (OPG) and the mean EPG and OPG were used for data analysis. The EPG/OPG was estimated using the modified McMaster technique with each counted eggs representing 200 eggs per gram of feces. ${ }^{8}$ The goats were grouped in 4 categories i.e., up to 3 months, $>3-6$ months, $>6-9$ months and $>9-12$ months of age. The goat owners in the two villages were grouped in 3 categories on the basis of their land holding capacity viz., landless (no land holding), small (with $<2$ acres land holding) and large holder (with $>2$ acres land holding). Size of goat flock was adjudged on the basis of number of animals. The flock size of the animals were classified as small $(<5$ animals), medium $(>5-10)$ and large $(>10$ animals) in both the villages. At each sampling time, bulk fecal samples were put for coproculture and the larvae identified. Likewise identification of Eimerian species was made by collection of oocysts and culturing them in 2 percent Potassium dichromate solution. Basis of identification was, however, morphology, micrometry and sporulation time. As faecal egg/oocyst counts were not normally distributed and because of skewed distribution, a set of logarithms transformation was applied to $\mathrm{EPG} / \mathrm{OPG}$ and the resulting transformed variables were tested for normality before analysis. ${ }^{4}$ All statistical tests for EPG/OPG were applied to the transformed data. The skewed distribution of fecal egg counts implied a $\log _{\mathrm{e}}$ $(\mathrm{EPG} / \mathrm{OPG}+100)$ transformation as it was found to be the most appropriate method to normalize the variance. The results were back transformed by taking anti-logarithms of the least-squares means (LSM) and presented as geometric means (GFEC).

The data were analyzed using mixed model least-squares analysis for fitting constants ${ }^{9}$ including all main effects and interaction, to overcome the difficulty of disproportionate sub class number and non-orthogonality of data. In the initial model, all 2-way interactions were included and all non-significant interactions were ignored in the final model:

$\mathrm{Y}_{\mathrm{ijklmnop}}=\mu+\mathrm{V}_{\mathrm{i}}+\mathrm{Y}_{\mathrm{j}}+\mathrm{S}_{\mathrm{k}}+\mathrm{H}_{\mathrm{l}}+\mathrm{F}_{\mathrm{m}}+\mathrm{X}_{\mathrm{n}}+\mathrm{A}_{0}$ $+(V Y)_{i j}+e_{i j k l m n o p}$

where,

$\mathrm{Y}_{\mathrm{ijklmnop}}$ is the record for the $\mathrm{p}^{\text {th }}$ animal

$\mathrm{V}_{\mathrm{i}}$ is the fixed effect of the $\mathrm{i}^{\text {th }}$ village

$Y_{j}$ is the fixed effect of the $j^{\text {th }}$ sampling year

$\mathrm{S}_{\mathrm{k}}$ is the fixed effect of the $\mathrm{k}^{\text {th }}$ sampling season $\mathrm{H}_{\mathrm{l}}$ is the fixed effect of the $\mathrm{I}^{\text {th }}$ land holding size $F_{m}$ is the fixed effect of the $m^{\text {th }}$ flock size $X_{n}$ is the fixed effect of the $n^{\text {th }}$ sex of animal $\mathrm{A}_{0}$ is the fixed effect of the $0^{\text {th }}$ age group of animal

$\mathrm{e}_{\mathrm{ijklmnop}}$ is the residual error element with standard assumptions.

\section{Results}

The common parasitic infections in both the villages were of similar nature. The goats, in general, showed coccidian, strongyle and moniezial infections.

\section{Coccidian infection}

The coccidian infection was of mixed nature showing presence of more than one species of Eimeria viz. Eimeria arliongi, E. ninakohlyakimovae, E. parva, E. caprina and E. alijevi in both the villages. The overall incidence of coccidian infection was 36.96 and 41.81 percent in Mahuan and Bhahai respectively (Table 1). The intensity of coccidian infection (OPG) varied significantly $(\mathrm{P}<0.01)$ in the two villages under study. The goats in Bhahai village had higher $(5.70 \pm 0.049)$ coccidian infection (no. oocyst/g feces) than the Mahuan village goats (5.48 \pm 0.050$)$. The load of coccidian infection in goats was also significantly varied according to the land holding of the goat farmers. The highest intensity of coccidian infection was observed in the flock of landless farmers $(5.79 \pm 0.06)$ followed by small $(5.59 \pm 0.050)$ and large $(5.39 \pm 0.060)$ farmers $(\mathrm{P}<0.05)$ (Table 1). The large flock size maintained by the farmers showed significantly $(\mathrm{P}<0.05)$ higher coccidian infection as compared to medium and small flocks. The overall incidence of coccidian infection in $0-3,>3-6,>6$ 12 and $>12$ month age groups was $36.32,46.11$, 47.01 and 34.68 percent respectively. The intensity of coccidian infection among animals was significantly $(\mathrm{P}<0.05)$ influenced by age of the animals. The higher intensity of coccid- ian infection of animals was observed in the age of 3-6 month $(5.67 \pm 0.06)$ and $6-12$ months $(5.78 \pm 0.10)$ as compared to animals of below 3 -months $(5.42 \pm 0.08)$ and adults $(5.46 \pm 0.05)$ (Table 1). The interaction effects between sampling village and sampling year only was significant $(\mathrm{P}<0.01)$ on load of coccidian oocysts of animals.

\section{Strongyle infection}

The copro-culture revealed that Haemonchus contortus was predominantly occurring nematode though the larvae of Trichostrongylus, Oesophagostomum and Strongyloides were also observed. The overall incidence of strongyle infection in Mahuan was 23.17 percent while the corresponding value in Bhahai village was 27.23 percent. Comparison of load of strongyle infection between these two villages revealed that goats in village Mahuan had significantly $(\mathrm{P}<0.01)$ lower load than village Bhahai goats $(5.09 \pm 0.05$ vs $5.21 \pm 0.05)$ (Table 1$)$. The load of strongyle infections in animals was also significantly varied among the flock of different sizes. The load of infection was higher in large flock size as compared to small and medium flock size. The overall incidence of strongyle infections in $0-3,>3-6,>6-12$ and $>12$ months was $14.34,20.72,31.12$ and 29.91 percent respectively (Table 1). Infection intensity was significantly $(\mathrm{P}<0.01)$ affected by the age of animals. Older animals (6-months or above) had significantly higher infection load as compared to younger animals (below 6 months of age). However, sampling year and season, land holding size of farmers, sex of animal and interaction effect had no significant $(\mathrm{P}>0.05)$ effects on intensity of strongyle infection of animals.

\section{Moniezial infection}

Both species of the Moniezia i.e. Moniezia expansa and $M$. benedini were present in goats in villages under study. The incidence of this infection in Mahuan was 8.96 percent while the corresponding value in Bhahai was 14.89 percent. The faecal moniezial egg count in Bhahai $(4.94 \pm 0.03)$ village was significantly higher than the Mahuan village $(4.81 \pm 0.03)$. Year wise analysis of load of moniezial egg count in goats revealed that there was significant variation in moniezial egg count among different sampling years under study and there was a definite increment trend of infection over the years. In this study, the flock size had significant $(\mathrm{P}<0.01)$ effect on load of moniezial infection in animals and animals in large flock showed higher incidence of moniezial infection in terms of higher FEC as compared to animals belonging to small and medium flock. The other environmental effects like land holding size, sampling month, age and sex of the animals and interaction effect were found non-significant on the load of Moniezial infection of animals. 


\section{Discussion and Conclusions}

Parasitic infections, coccidian and helminthic both, are quite common and major constraints in small ruminant production. The infection may be concurrent or single.3,4,10 Various factors, genetic as well as environ- mental, play important role in parasitic infections in goats both in natural and captive conditions.

The findings of the present study on incidence on parasitic infections were similar to the findings of previous studies conducted in this region. ${ }^{11}$ The variations of intensity of infections in two villages, Mahuan and Bhahai can be attributed to variation in local ecological factors existing in them. Significantly higher load of coccidian oocysts in larger size herds in both the villages indicated the higher stocking rate in larger size flock which might have resulted increase in frequency and quantum of infection available in surrounding for animal. Further statistically similar LSM of coccidian

Table 1. Least squares means of different parasitic infections in goats in adopted villages.

\begin{tabular}{|c|c|c|c|c|}
\hline Parameters & $\begin{array}{l}\text { No. of } \\
\text { Obs. }\end{array}$ & $\begin{array}{l}\text { Coccidian infection Loge } \\
(\mathrm{OPG}+100)(\mathrm{GFEC})^{*}\end{array}$ & $\begin{array}{l}\text { Strongyle infection } \\
\text { (EPG) (GFEC) }\end{array}$ & $\begin{array}{l}\text { Moniezial infection } \\
\text { (EPG) (GFEC) }\end{array}$ \\
\hline Overall & 1452 & $5.58 \pm 0.04(166.2)^{*}$ & $5.15 \pm 0.04(73.0)$ & $4.87 \pm 0.02(30.6)$ \\
\hline \multicolumn{5}{|c|}{ Sampling village } \\
\hline Mahuan (V1) & 725 & $5.47 \pm 0.05 \mathrm{a}(138.1)$ & $5.09 \pm 0.05 \mathrm{a}(61.9)$ & $4.81 \pm 0.03 \mathrm{a}(22.3)$ \\
\hline Bhahai (V2) & 727 & $5.70 \pm 0.05^{b}(197.6)$ & $5.21 \pm 0.05^{b}(84.8)$ & $4.94 \pm 0.03 \mathrm{~b}(39.4)$ \\
\hline \multicolumn{5}{|c|}{ Year of collection } \\
\hline 1999 (Y1) & 402 & $5.53 \pm 0.07 \mathrm{a}(152.4)$ & $5.11 \pm 0.06 \mathrm{a}(65.3)$ & $4.78 \pm 0.04 \mathrm{~b}(19.7)$ \\
\hline 2000 (Y2) & 360 & $5.60 \pm 0.07 \mathrm{a}(169.8)$ & $5.15 \pm 0.06 \mathrm{a}(72.8)$ & $4.87 \pm 0.04 \mathrm{ab}(30.3)$ \\
\hline 2001 (Y3) & 346 & $5.58 \pm 0.07 \mathrm{a}(164.3)$ & $5.16 \pm 0.06^{\mathrm{a}}(74.6)$ & $4.88 \pm 0.04^{\mathrm{ab}}(31.3)$ \\
\hline 2002 (Y4) & 344 & $5.63 \pm 0.07 \mathrm{a}(179.1)$ & $5.19 \pm 0.06 \mathrm{a}(79.6)$ & $4.96 \pm 0.04 \mathrm{a}(42.0)$ \\
\hline \multicolumn{5}{|c|}{ Season of sampling } \\
\hline Winter & 134 & $5.63 \pm 0.06^{\mathrm{a}}(179.1)$ & $5.10 \pm 0.05^{\mathrm{a}}(63.6)$ & $4.83 \pm 0.03^{\mathrm{a}}(24.9)$ \\
\hline Summer & 116 & $5.55 \pm 0.06 \mathrm{a}(158.1)$ & $5.22 \pm 0.05^{\mathrm{a}}(85.2)$ & $4.85 \pm 0.03 \mathrm{a}(28.0)$ \\
\hline Rainy & 121 & $5.64 \pm 0.07 \mathrm{a}(180.7)$ & $5.15 \pm 0.06 \mathrm{a}(72.9)$ & $4.89 \pm 0.04 \mathrm{a}(33.4)$ \\
\hline Autumn & 123 & $5.51 \pm 0.11 \mathrm{a}(148.4)$ & $5.14 \pm 0.10 \mathrm{a}(70.8)$ & $4.92 \pm 0.06 \mathrm{a}(36.4)$ \\
\hline \multicolumn{5}{|c|}{ Land holding size of farmers } \\
\hline Landless & 471 & $5.79 \pm 0.06 \mathrm{a}^{\mathrm{a}}(226.2)$ & $5.17 \pm 0.05^{a}(75.6)$ & $4.88 \pm 0.04 \mathrm{ab}(31.8)$ \\
\hline Small & 558 & $5.59 \pm 0.06^{\mathrm{b}}(167.1)$ & $5.14 \pm 0.05 \mathrm{a}(70.5)$ & $4.81 \pm 0.03 \mathrm{~b}(22.9)$ \\
\hline Large & 423 & $5.38 \pm 0.06 \mathrm{c}(116.6)$ & $5.15 \pm 0.06 \mathrm{a}(72.8)$ & $4.92 \pm 0.04 \mathrm{a}(37.5)$ \\
\hline \multicolumn{5}{|c|}{ Flock size } \\
\hline Small & 455 & $5.18 \pm 0.06 \mathrm{a}(77.8)$ & $4.97 \pm 0.06 \mathrm{a}(43.6)$ & $4.79 \pm 0.04 \mathrm{~b}(20.2)$ \\
\hline Medium & 522 & $5.30 \pm 0.06 \mathrm{a}(100.6)$ & $5.00 \pm 0.05 \mathrm{a}(48.1)$ & $4.83 \pm 0.03 \mathrm{~b}((25.8)$ \\
\hline Large & 475 & $6.27 \pm 0.06^{\mathrm{b}}(429.1)$ & $5.49 \pm 0.05 \mathrm{~b}(143.4)$ & $4.99 \pm 0.03 \mathrm{a}(47.3)$ \\
\hline \multicolumn{5}{|c|}{ Sex of animal } \\
\hline Female & 493 & $5.63 \pm 0.06 \mathrm{a}(179.7)$ & $5.14 \pm 0.05 \mathrm{a}(70.7)$ & $4.88 \pm 0.03 \mathrm{a}(31.3)$ \\
\hline Male & 959 & $5.53 \pm 0.05^{\mathrm{a}}(153.4)$ & $5.17 \pm 0.04 \mathrm{a}(75.3)$ & $4.87 \pm 0.03 \mathrm{a}(29.9)$ \\
\hline \multicolumn{5}{|c|}{ Age of animals } \\
\hline $0-3$ months & 223 & $5.42 \pm 0.08 \mathrm{a}(126.6)$ & $4.95 \pm 0.07 \mathrm{a}(41.1)$ & $4.86 \pm 0.05^{a}(29.4)$ \\
\hline 3-6 months & 386 & $5.67 \pm 0.06^{\mathrm{b}}(190.5)$ & $5.06 \pm 0.06^{a}(56.9)$ & $4.86 \pm 0.04 \mathrm{a}(29.3)$ \\
\hline 6-12 months & 151 & $5.78 \pm 0.10^{\mathrm{b}}(222.9)$ & $5.31 \pm 0.09 \mathrm{~b}(101.9)$ & $4.90 \pm 0.06^{\mathrm{a}}(33.7)$ \\
\hline Adult & 692 & $5.46 \pm 0.05 \mathrm{a}(136.3)$ & $5.30 \pm 0.04 \mathrm{~b}(100.3)$ & $4.87 \pm 0.03 \mathrm{a}(30.0)$ \\
\hline \multicolumn{5}{|c|}{ Interaction } \\
\hline $\mathrm{V} 1 \times \mathrm{Y} 1$ & 224 & $5.49 \pm 0.08 \mathrm{bc}(142.6)$ & $5.12 \pm 0.07 \mathrm{a}(67.0)$ & $4.78 \pm 0.05^{\mathrm{a}}(19.2)$ \\
\hline $\mathrm{V} 1 \times \mathrm{Y} 2$ & 169 & $5.56 \pm 0.10$ bc $(160.3)$ & $5.07 \pm 0.08 \mathrm{a}(58.9)$ & $4.80 \pm 0.05 \mathrm{a}(21.5)$ \\
\hline $\mathrm{V} 1 \times \mathrm{Y} 3$ & 170 & $5.45 \pm 0.10$ bc $(132.7)$ & $5.07 \pm 0.08 \mathrm{a}(59.0)$ & $4.79 \pm 0.05 \mathrm{a}(20.8)$ \\
\hline $\mathrm{V} 1 \times \mathrm{Y} 4$ & 162 & $5.39 \pm 0.10 \mathrm{c}(118.8)$ & $5.09 \pm 0.08 \mathrm{a}(62.8)$ & $4.85 \pm 0.05^{\mathrm{a}}(28.0)$ \\
\hline $\mathrm{V} 2 \times \mathrm{Y} 1$ & 178 & $5.57 \pm 0.09 \mathrm{bc}(162.7)$ & $5.10 \pm 0.08 \mathrm{a}(63.5)$ & $4.79 \pm 0.05 \mathrm{a}(20.2)$ \\
\hline $\mathrm{V} 2 \times \mathrm{Y} 2$ & 191 & $5.63 \pm 0.09 \mathrm{ac}(179.6)$ & $5.24 \pm 0.08 \mathrm{a}(87.9)$ & $4.94 \pm 0.05^{a}(39.8)$ \\
\hline $\mathrm{V} 2 \times \mathrm{Y} 3$ & 176 & $5.70 \pm 0.09 \mathrm{a}(200.1)$ & $5.26 \pm 0.08 \mathrm{a}(91.7)$ & $4.96 \pm 0.05^{\mathrm{a}}(42.7)$ \\
\hline $\mathrm{V} 2 \times \mathrm{Y} 4$ & 182 & $5.88 \pm 0.09 \mathrm{a}(256.1)$ & $5.29 \pm 0.08 \mathrm{a}(98.1)$ & $5.06 \pm 0.05^{\mathrm{a}}(57.6)$ \\
\hline
\end{tabular}

*Units eggs/g; the mean of loge value is given first followed by its antilog in the parenthesis. Means with different letters differed significantly $(\mathrm{P}<0.05)$ from each other. OPG, oocysts per gm feces; $\mathrm{EPG}$, eggs per gm. Faeces; Loge $(\mathrm{OPG}+100)$, natural log of OPG/EPG when added 100; LFEC, Log transformed faecal oocysts/eggs count; GFEC, geometric means of fecal oocysts/eggs count; V1, village 1; V2, village 2. 
oocysts counts in small and medium size herd showed that menace of coccidiosis need to be managed in flocks having 10 or more number of animals. The significant higher OPG counts in 3-6M age group in present study were similar as reported in previous studies.4,11,12 The difference in load of coccidian oocysts in herds of land less, small and large land holders was significant from epidemiological point of view. Though land holding of farmer seems not having direct effect on coccidian infection, however, it leaves an impact upon the farmer's income which in term directly determine the quality of livestock management like better sanitation, better living space, better nutrition and better health care. Contrary to our belief, the animals with large land holders in present study were found to have significantly lower OPG count. This may, however, be attributed to the fact that large sized herd were maintained by landless farmers. Study on effect of land holding of farmer on parasitic infection lack reports and could not be corroborated with literature support. No significant effect of factors like year and month of collection of samples on oocysts output showed that both the villages were in similar environment zone with little impact on coccidian load. 13

The prevalence of strongyle infection in both the villages was comparable, however, it appeared to be low in comparison to some of the previous reports.4,14 The significantly different LFEC, the means of log transformed egg counts, in both the villages can be explained on the basis of local factors like availability of grazing pasture land and their quality. The local water logging conditions in Bhahai village in large portion of the year would have contributed to higher mean epg among goats in this village. Size of the herd in term of number of animals, showed significant effect on LFEC and the flocks with >10 animals had significantly high EPG in comparison of other two smaller size flocks. Though, strongyle infection in small ruminants has pasture origin yet the number of animals in flock in term of stocking would have been determining the quantum of strongyle infection (Hoste, 2005). 15 Significantly higher LFEC in older age flocks i.e. $6-12 \mathrm{M}$ and adult in comparison to lower age flocks was similar to previous reports, 4,11 and may be attributed to preponderance of the Haemonchus contortus in nematode infections which affects higher age small ruminants. The non significant effect of year of sampling in present study was, however, in contrast to author's previous report 4 in organized flock of Jakhrana goats. The variation in results, however, can be attributed to varied environment influencing the development and availability of $\mathrm{L}_{3}$ on pasture.
Prevalence of moniezial infection in two villages was comparable. However, it was lower than the $25 \%$ prevalence reported from Bangladesh, ${ }^{16}$ and higher than 1.97 percent reported from Bidar Karnataka in India. ${ }^{17}$ Both previous studies reported both the species observed in the present study. Moniezial being a beetle borne infection, its prevalence in small ruminants is determined by dynamics of beetle population. 18 The significant difference in mean moniezial egg count in two villages can be explained on the basis of population intensity of intermediate host which is determined by hygienic management of the herd. Effect of sampling year on LFEC in moniezial infection was significant and increasing trend of moniezial infection was observed over the period. The moniezial LFEC was significantly low in flocks maintained by small land holders. The finding however was interesting as small land holder preferred feeding their animals by lopping against ground feeding or grazing in pasture by the other two types of flocks. Significantly higher LFEC in large sized flock (>10 animals) than the lower sized flocks can be explained as the flock hygiene was more vulnerable due to being more number of animals in large flock.

Epidemiology of parasitic infections in an ecosystem plays important role in their control and management. The information revealing the effects of age of the animal, flock size, farmers' land holding generated in present study, are of practical relevance directly as well as indirectly to overcome the production losses in animals due to parasites implication.

\section{References}

1. de la Fuente C, Cuquerella M, Carrera L, et al. Effect of sub-clinical coccidiosis in kids on subsequent trichostrongylid infection after weaning. Vet Parasitol 1993;45:17783.

2. Borgsteede FHM, Dercksen DP. Coccidial and helminth infections in goats kept indoors in The Netherlands. Vet Parasitol 1996;61:321-6.

3. Rahman WA. Effect of sub clinical Eimeria species infections in tropical goats subsequently challenged with caprine Haemonchus contortus. Vet Record 1994; 134:235-7.

4. Sharma DK, Agrawal N, Mandal A, et al. Coccidia and gastrointestinal nematode infections in semi-intensively managed Jakhrana goats of semi-arid region of
India. Trop Subtrop Agroecosystems 2009;11:135-2395.

5. Mandal A, Sharma DK. Inheritance of faecal nematode egg count in Barbari goats following natural Haemonchus contortus infection. Vet Parasitol 2008;155:89-94.

6. Mandal A, Agrawal N, Nigam P, et al. Susceptibility of Haemonchus contortus infection in Jakhrana goats. Ind J Anim Sci 2011;81:149-51

7. Rout PK, Chauhan KK, Matika 0, et al. Exploring the genetic resistance to natural gastrointestinal nematode infection in Indian goats. Vet Parasitol 2011;180:31522.

8. MAFF. Manual of veterinary parasitological techniques. Technical Bulletin No. 18. London: Her Majesty's Stationery Office; 1986. p 129.

9. Harvey WR. User's Guide for LSMLMW MIXMDL, PC-2I Version. Columbus: 1990.

10. Faizal ACM, Rajapakshe RPVJ. Prevalence of coccidia and gastrointestinal nematodes in crossbred goats in the dry areas of Sri Lanka. Small Rumin Res 2001;40:2338.

11. Sharma DK, Singh N. Mortality among goats due to parasitic infestations: a post mortem analysis. Ind J Anim Sci 1997;67: 463-5

12. Padilla MA, Baticados WN, Desamero JM et al. Prevalence and factors associated with Eimeria infection in goats in Laguna, Philippines. Philippine J Vet Anim Sci 2009;35:108-18.

13. Vercruysse J. The coccidia of sheep and goats in Senegal. Vet Parasitol 1982;10: 297-306.

14. Bitew M, Amde Y, Belachew K. Abomasal and intestinal nematodes of small ruminants slaughtered in different restaurants in Hawassa. Vet Res 2011;4:39-44.

15. Hoste H. Alternative methods for the sustainable control of gastrointestinal nematodes in small ruminants, Options Méditerranéenes Série A: Séminaires Méditerranéens 2005;67:431-6.

16. Gupta SD, Sarkar PK. Measuring the frequency of gastrointestinal helminth infection in goats and their risk factors. J Subtrop Agricult Res Develop 2007;5:2115.

17. Thangathurai R, Rao DGK. Occurrence of enteric parasitism of goats in Bidar region (Karnataka). Ind J Anim Health 2002;41: 151-2.

18. Kaur A, Rai HS, Singh NK. Prevalence of oribatid mites and its correlation with cestodes of veterinary importance in Ludhiana. J Vet Parasitol 2007;21:149-52. 